WellBeing International

WBI Studies Repository

2018

\title{
Encouraging Self-Reflection by Veterinary Clinicians: Ethics on the Clinic Floor
}

\author{
Sandra A. Corr \\ University of Glasgow \\ Clare Palmer \\ Texas A \& M University - College Station \\ Peter Sandøe \\ University of Copenhagen
}

Follow this and additional works at: https://www.wellbeingintlstudiesrepository.org/vm_ethics

\section{Recommended Citation}

Corr, Sandra A.; Palmer, Clare; and Sandøe, Peter, "Encouraging Self-Reflection by Veterinary Clinicians: Ethics on the Clinic Floor" (2018). Veterinary Medicine - Ethics. 1.

https://www.wellbeingintlstudiesrepository.org/vm_ethics/1

This material is brought to you for free and open access by WellBeing International. It has been accepted for inclusion by an authorized administrator of the WBI Studies Repository. For more information, please contact wbisr-info@wellbeingintl.org.

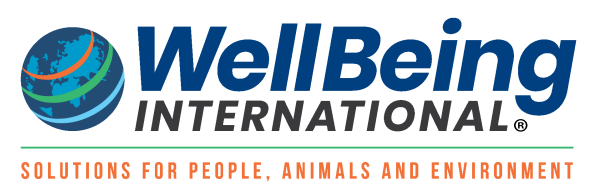




\section{Encouraging Self-Reflection by Veterinary Clinicians: Ethics on the Clinic Floor}

\section{Sandra A. Corr, Clare Palmer \& Peter Sandøe}

To cite this article: Sandra A. Corr, Clare Palmer \& Peter Sandøe (2018) Encouraging SelfReflection by Veterinary Clinicians: Ethics on the Clinic Floor, The American Journal of Bioethics, 18:2, 55-57, DOI: $10.1080 / 15265161.2017 .1409843$

To link to this article: https://doi.org/10.1080/15265161.2017.1409843

\section{Published online: 02 Feb 2018.}

\section{Submit your article to this journal $匚$}

山ll Article views: 168

Q View related articles ๘

View Crossmark data $₫$ 
"pet parents." At the same time, veterinary medicine has advanced exponentially in its sophistication and in the level of intervention that may be leveraged on behalf of an animal patient. Hence we witness the emergence of tertiary care facilities as described by Rosoff and colleagues (2018). With increased medical sophistication come attendant decisional challenges from multiple perspectivesthe pet's perspective, the pet owner's perspective, and the veterinary health care provider's perspective. There is a need for a formal strategy to guide challenging medical decision making.

While the translation and adaptation of the human medical model of the CEC is a reasonable first step for veterinary tertiary care facilities to adopt (and, we would argue, for primary care facilities to consider as well), the overarching dilemmas remain, and may be ultimately unresolvable. The interests of humans always come first, with the interests of companion animals remaining secondary. The veterinary medical care of animal patients will always be viewed through the lens of human interests. And animal medical decisions hinge on the pet owners' interpretations of the medical recommendations and their own abilities to provide care. Rosoff and colleagues (2018) articulate that their adaptation is a first step, and describe their approach as "novel and experimental." We eagerly await follow-up reporting from the authors as this model is used in the tertiary care practice at the veterinary teaching hospital at North Carolina State University.

\section{REFERENCES}

Andrews, K. 2011. Beyond anthropomorphism: Attributing psychological properties to animals. In The Oxford handbook of animal ethics, ed. T. L Beauchamp and R. G. Frey, 469-94. New York, NY: Oxford University Press.
Jonsen, A. R., M. Siegler, and W. J. Windslade. 2015. Clincal ethics, A practical approach to ethical decisions in clinical medicine, 8th ed. New York, NY: McGraw-Hill Education.

McMillan, F. D. 2003. Maximizing quality of life in ill animals. Journal of the American Animal Hospital Association 39:227-35. doi:10.5326/0390227.

McMillan, F. D. 2005. The concept of quality of life in animals. In Mental health and well-being in animals, ed. F. D. McMillan, 183-200. Ames, IA: Blackwell .

Molony, V. 1997. Commentary. Pain 70:293. doi:10.1097/00006396199704000-00031.

Nussbaum, M. 2011. The capabilities approach and animal entitlements. In The Oxford handbook of animal ethics, ed. T. L. Beauchamp and R. G. Frey, 228-54. New York, NY: Oxford University Press.

Panskeep, J., D. Reiss, P. Low et al., eds. 2012. Low P. Cambridge declaration of consciousness. Presented at the Francis Crick Memorial Conference on Consciousness in Human and NonHuman Animals at Churchill College, University of Cambridge, Cambridge, UK, July.

Rollin, B. E. 2005. On understanding animal mentation. In Mental health and well-being in animals, ed. F. D. McMillan, 3-14. Ames, IA: Blackwell .

Rosoff, P. M., J. Moga, B. Keene, et al. Resolving ethical dilemmas in a tertiary care veterinary specialty hospital: Adaptation of the human clinical consultation committee model. American Journal of Bioethics 18 (2):41-53.

Ryder, R. D. 2000. Animal revolution: Changing attitudes towards speciesism. Oxford, UK: Berg.

Ryder, R. D. 2001. Painism: A modern morality. London, UK: Centaur Press.

Serpell, J. 1996. In the company of animals: A study of human-animal relationships. Cambridge, UK: Cambridge University Press.

\title{
Encouraging Self-Reflection by Veterinary Clinicians: Ethics on the Clinic Floor
}

\author{
Sandra A. Corr, University of Glasgow \\ Clare Palmer, Texas A \& M University \\ Peter Sandøe $\complement^{\circ}$, University of Copenhagen
}

Rosoff and colleagues (2018) describe some difficult ethical decisions facing veterinarians in clinics treating dogs, cats, and other companion animals. They propose adapting the human clinical consultation committee model, and establishing clinical ethics committees (CECs) to assist in resolving such ethical challenges in the more advanced of these

Address correspondence to Peter Sandøe, University of Copenhagen, Department of Food and Resource Economics, Rolighedsvej 25, 1958 Frederiksberg C, Denmark. E-mail: pes@sund.ku.dk 
clinics, the so-called tertiary care veterinary specialty hospitals.

In this commentary, we agree that veterinarians often face troubling ethical decisions involving potential overor undertreatment of their animal patients, the financial constraints of their clients, and, sometimes, the goals of the institutions that employ them. While we accept that a CEC may, in some contexts, be an appropriate structure in which to deal with such difficult decisions, we argue that this is not the only, or necessarily the best, approach. We suggest that the ethical problems facing veterinarians differ significantly in different countries; that many acute ethical issues typically arise before animals even arrive at the veterinary specialty hospital; and that even within such hospitals, approaches other than CECs might be more effective, especially at gaining acceptance by the veterinarians themselves.

The context of Rosoff and colleagues' (2018) account is rather United States centered. Cultural norms and legal requirements around animal treatments, and especially euthanasia, vary significantly by country. In many European countries, for example, veterinary decisions about the life and death of companion animal patients are much more constrained by legal frameworks. While in the United States and Canada euthanasia of healthy animals for owner convenience is legally permitted, in countries such as Austria and Germany it is not allowed. Conversely, in these and many other European countries, including the Scandinavian countries and the United Kingdom, veterinarians are obliged by law to euthanize a severely ill animal if continuing treatment will not cure or effectively alleviate symptoms and would thereby prolong unnecessary suffering. While such legal constraints do not entirely resolve dilemmas around animal euthanasia, they certainly reframe them in a way that alleviates some of the burdens otherwise carried by veterinarians.

Rosoff and colleagues focus their discussion at the level of tertiary care (advanced treatment) at a university veterinary hospital, and suggest that the complex ethical issues raised by such care are of little relevance to, and rarely impact on, primary care veterinarians. Although some cases may come from the hospital's own emergency admissions, the majority are usually referred from a primary (or secondary) care veterinarian, and we argue that a key ethical decision is made by the referring veterinarian, in consultation with the owner, before the animal arrives at the specialty tertiary hospital.

Embarking on the referral process implies an emotional and financial commitment on the part of the owner to investigate and/or treat the animal. Careful reflection by the referring veterinarian at this stage could avoid some of the most difficult dilemmas in the specialist hospital. For example, an owner may wish referral for treatment of a dog with cancer that has already metastasized to the lungs. Here, referring veterinarians must recognize the effect of "framing": The manner in which they present the treatment options and prognosis will strongly influence the owner's subsequent decision. In making such recommendations, referring veterinarians have significant ethical obligations to consider whether referral is likely to be in the best interests of both their animal patients and human clients. Once the animal patient is referred for advanced care, it becomes increasingly difficult for treatment to be reconsidered, due to the aforementioned emotional and financial investment by the owner and, to some degree, the professional investment of the specialist veterinarian(s). Veterinarians (at all levels) should be encouraged and supported to reflect on their underlying motivations for recommending or undertaking advanced treatments.

Of course, difficult ethical decisions will still present themselves in the hospital. We recognize that a CEC has obvious merit in dealing with some of these problems, yet Rosoff and colleagues report that the CEC did not seem to be much used ("several times" over a period of 6 months). This may be because many ethical dilemmas are not striking or grand, at a level requiring committee action, but rather, small-scale and cumulative; for these, a CEC may not be the best tool. An alternative - or perhaps complementary-approach would aim to embed ethical thinking on a day-to-day basis on the clinic floor, among the team directly responsible for the patient's treatment. Arguably, a CEC may discourage this, by seeming to delegate responsibility elsewhere, and such a committee may be resisted by clinicians who do not want treatment decisions taken out of their hands.

Despite the expansion of ethical teaching in veterinary undergraduate training, discussion of ethical concerns and questions is still, to our knowledge, not very common on the clinic floor. One way of making the consideration of ethical concerns routine could be by introducing ethical checklists, to be used by veterinarians at key points in the treatment of an animal. A checklist would be a way of giving structure to, and expanding on, many of the questions that veterinarians already ask, including: Would treatment really be in the animal's interest? What is the expected end state for this animal? What does the animal have to go through on the way? Has an endpoint for treatment been agreed upon? What are the needs and emotional commitments of the owner? Is the owner able, economically and practically, to do what is needed? Are there consequences for other animals or humans? A critical step here is to establish whether a "good outcome" or a "reasonable chance" is interpreted in the same way by both the veterinarian and the owner, and to identify and agree endpoints at which treatment would be stopped and euthanasia be performed. Such a process would significantly improve informed consent and shared decision-making between veterinarians and owners, and should help to reduce the potential for more acute ethical dilemmas later. In addition, it brings clearly into focus all the impacts treatment or euthanasia may bring, for the human client, for the companion animal, for other family members, and with regard to the personal and professional responsibilities of the vet her- or himself.

Rosoff and colleagues argue that sometimes treatment is urgent, and owners have to make difficult decisions very quickly. For instance, suppose a cat came in to a specialist unit with severe injuries after being hit by a car: fractured 
ribs, a collapsed lung, internal hemorrhage, and multiple limb bone fractures. Heroic measures are taken by the intensive care team to keep the cat alive overnight. However, in doing this, all the owner's available finances are exhausted, and the owner cannot then afford to pay for the fracture repairs. In this case, the cat and the owner have been done a severe disservice. In such circumstances, an ethical checklist could have facilitated a discussion with the client before the heroic measures are taken, ensuring that the costs of all the likely treatments were known, and endpoints agreed, in advance. This would help "rationalize" decision making at a time of heightened emotions, potentially avoiding decisions that could raise later ethical problems, and subsequent regret on the part of the owner and/or vet.

Embedding ethical discussion in routine veterinary practice, and making use of ethical checklists, may be of considerable help to veterinarians who feel that they are left alone to make extremely difficult and stressful decisions about treatment-for instance, with clients who are deeply attached to their animals, or who are unable to afford advanced treatment for them. For such ethical discussion to be widely accepted, however, senior staff in a clinic must take the lead, by modeling behavior in which ethical reflection on treatment choices becomes an integral part of the management of every case. Well-motivated decisions taken by CECs can also feed into this type of ethical reflection. Of course, an ethical checklist or similar tool will not ensure that consensus is achieved about the right way to handle the dilemmas faced in veterinary practice, as much depends upon the underlying ethical perspective of the people using it. However, the advantage is that disagreements about weightings may be addressed in a transparent manner, with an explicit focus on how the various parties are likely to be affected by decisions taken.

We share with Rosoff and colleagues a concern for helping veterinarians in clinics to handle the difficult ethical dilemmas they face. There is here, in our view, a clear need for more empirically based research on how veterinarians and clients actually perceive and try to deal with these dilemmas (for examples of this kind of research cf. Kondrup et al. 2016; Christiansen et al. 2016). As such, it would be interesting to read a follow-up article that documents and reviews the uptake and effectiveness of veterinary CECs.

\section{ORCID}

Peter Sandøe (iD http:/ /orcid.org/0000-0003-0397-3273

\section{REFERENCES}

Christiansen, S. B., A. T. Kristensen, J. Lassen, and P. Sandøe. 2016. Veterinarians' role in clients' decision-making regarding seriously ill companion animal patients. Acta Veterinaria Scandinavica 58:30. doi:10.1186/s13028-016-0211-x.

Kondrup, S. V., K. P. Anhøj, C. Rødsgaard-Rosenbeck, T. B. Lund, M. H. Nissen, and P. Sandøe. 2016. Veterinarian's dilemma: A study of how Danish small animal practitioners handle financially limited clients. Veterinary Record 179:596. doi:10.1136/vr.103725.

Rosoff, P. M., J. Moga, B. Keene, et al. 2018. Resolving ethical dilemmas in a tertiary care veterinary specialty hospital: Adaptation of the human clinical consultation committee model. American Journal of Bioethics 18 (2):41-53.

\section{Limits to Applying Lessons from Medical Ethics to Veterinary Ethics}

\section{Bruce D. White, Albany Medical College}

Rosoff and his colleagues at the North Carolina State Veterinary Specialty Hospital in Raleigh should be congratulated for establishing the first clinical ethics committee (CEC) within a veterinary hospital (Rosoff et al. 2018). For any who have participated in offering clinical ethics consultation services over the past 30 or so years in human medicine facilities, it is interesting to see how the field is extending its influence in new directions to improve delivery models for better health.
However, some-having grown up in rural America where fathers put down farm animals and pets without even thinking about involving a veterinarian-may initially find new developments such as veterinary intensive care units and veterinary hospital ethics committees as odd, or certainly curious. ${ }^{1}$ Regardless, what is remarkably positive is the clear recognition among some veterinary practitioners that even though they can do something,

1. Nathan Muir: [inside a CIA briefing room] When I was a kid I used to spend summers on my uncle's farm. And he had this plow horse he used to work with everyday. He really loved that plow horse. One summer she came up lame. It could barely stand. The vet offered to put her down. You know what my uncle said?

Charles Harker: No, Muir, what did he say?

Nathan Muir: He said, why would I ask somebody else to kill a horse that belonged to me? (Beckner and Arata 2001)

Address correspondence to Bruce D. White, Alden March Bioethics Institute, Albany Medical College, 47 New Scotland Avenue, MC 153, Albany, NY 12298, USA. E-mail: brucedwhite@mac.com 